\title{
Tumor de células granulares esclerosante de mama simulando fibromatose
}

Sclerosing granular cell tumor of the breast simulating fibromatosis

Eddie Fernando Candido Murta, Délcio Scandiuzzi,

Ana Cristina Premoli, Luciana de Sousa Batista Leite, Ana Lúcia Kefalás de Oliveira Melo, Marcus Aurélio de Lima

\section{RESUM0}

Descrevemos um caso de tumor de células granulares esclerosante de mama simulando, histologicamente, fibromatose. Clinicamente, simulava um carcinoma pela consistência fibrosa e fixação ao músculo peitoral maior. O exame mamográfico demonstrou uma densificação parenquimatosa e mal definida na união dos quadrantes superiores da mama esquerda. $O$ exame ultra-sonográfico demonstrou uma lesão sólida mal definida aderente ao músculo peitoral. Os aspectos clínicos, radiológicos, histopatológicos e terapêuticos do tumor são discutidos.

PALAVRAS-CHAVE: Mama: doenças benignas. Tumor de células granulares esclerosante. Fibromatose.

\section{Introdução}

O tumor de células granulares (TCG) originase provavelmente das células de Schwann, é geralmente benigno e costuma ser achado incidental durante exame físico de rotina por alguma outra causa. O TCG ocorre em pacientes de qualquer idade, principalmente mulheres e, comumente, as lesões manifestam-se como nódulos na derme ou subcutâneo e menos freqüentemente, na submucosa, músculo liso ou estriado, podendo se originar em qualquer localização sendo mais encontrado na língua, tórax e membros superiores.

Disciplinas de Ginecologia e Obstetrícia, Imagenologia e Patologia Especial da Faculdade de Medicina do Triângulo Mineiro

Correspondência:

Eddie Fernando Cândido Murta - Disciplina de Ginecologia e Obstetrícia da FMTM

Av. Getúlio Guaritá, s/no - Abadia - 38025-440 - Uberaba-MG

Fone (034) 318-5326 - FAX (034) 333-8710

E-mail: eddiemurta@mednet.com.br
A mama é a sede em 5\% dos casos de TCG e pode ser confundido nessa localização com carcinoma $^{2,6,10}$.

Nós tivemos oportunidade de tratar uma paciente com TCG de padrão esclerosante de mama, que em virtude de sua raridade e do diagnóstico diferencial com fibromatose, histologicamente, achamos por bem relatá-lo, abordando aspectos clínicos, radiológicos, histopatológicos e terapêuticos do tumor.

\section{Relato do caso}

Mulher negra, 70 anos, casada, procurou o serviço de mastologia queixando-se de nódulo na mama esquerda. Antecedentes ginecológicos: menarca aos 11 anos, 4 gestações e 4 partos normais (primeira gestação aos 22 anos), amamentou todos os filhos. Antecedentes familiares: não há história de neoplasia ginecológica 
ou quaisquer outras. Antecedentes pessoais: nega tabagismo e alcoolismo. Ao exame físico evidenciouse abaulamento difuso do quadrante superior externo da mama esquerda. À palpação, o parênquima apresentava-se com tumoração profunda retromamária de $6 \mathrm{~cm}$ de diâmetro, limites imprecisos e superfície irregular, duro, fixo ao músculo peitoral maior. Não foram observados linfonodos significativos. Com estes dados, a hipótese diagnóstica foi de carcinoma na mama esquerda, estádio IIB (T3 NO).

A mamografia identificou o nódulo como retroareolar profundo, tendo dificuldades em definilo radiologicamente por estar posteriorizado e aderido aos planos profundos (Figura 1). Tal definição foi conseguida pelo ultra-som: contornos irregulares e localização retroareolar profunda (Figura 2). A hipótese diagnóstica pós-exames de imagem da radiologia persistiu como neoplasia de mama esquerda. A paciente foi submetida à punção biópsia aspirativa com agulha fina e em razão da presença de pouco material não foi possivel o diagnóstico.

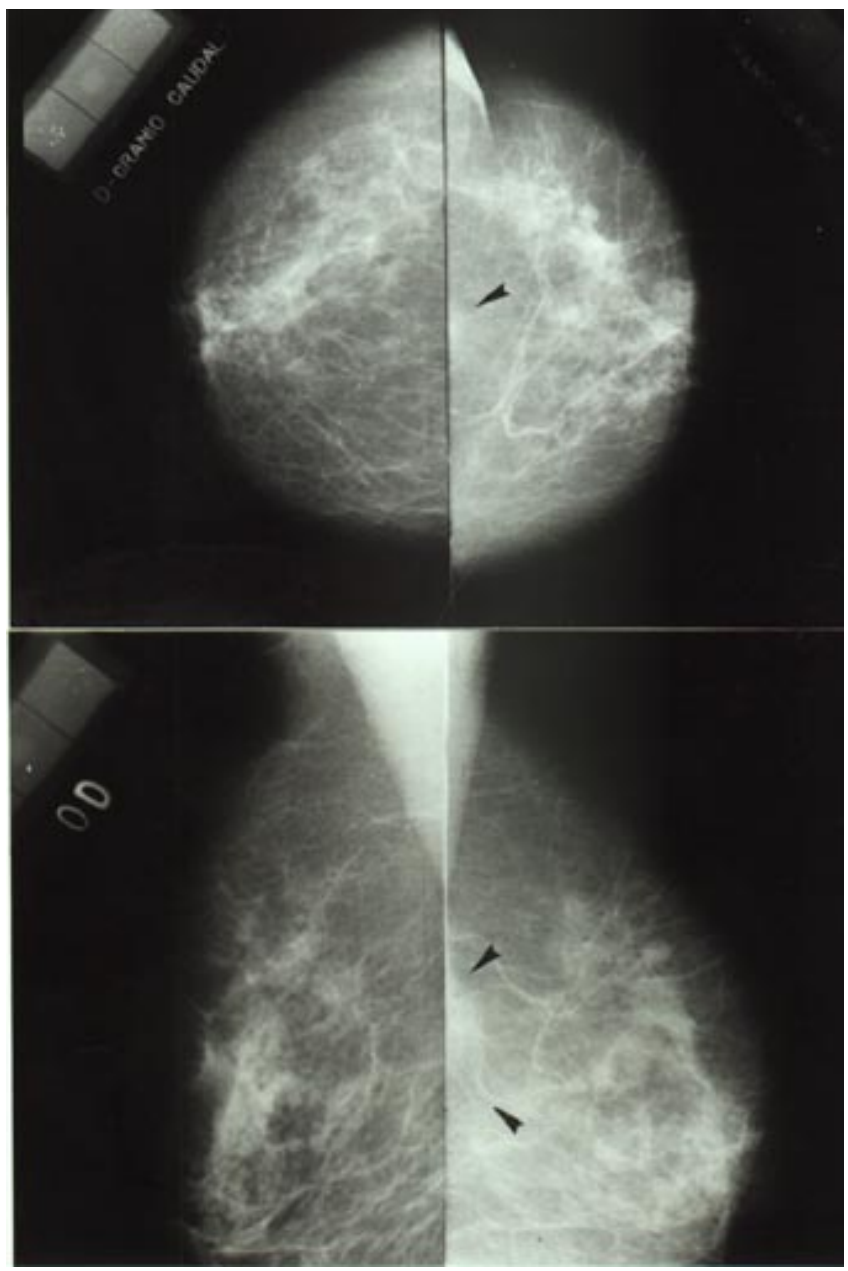

Figura 1 - Mamografia (incidências crânio-caudal e oblíqua): densificação assimétrica e mal definida na junção dos quadrantes superiores, profunda e adjacente ao músculo peitoral maior.

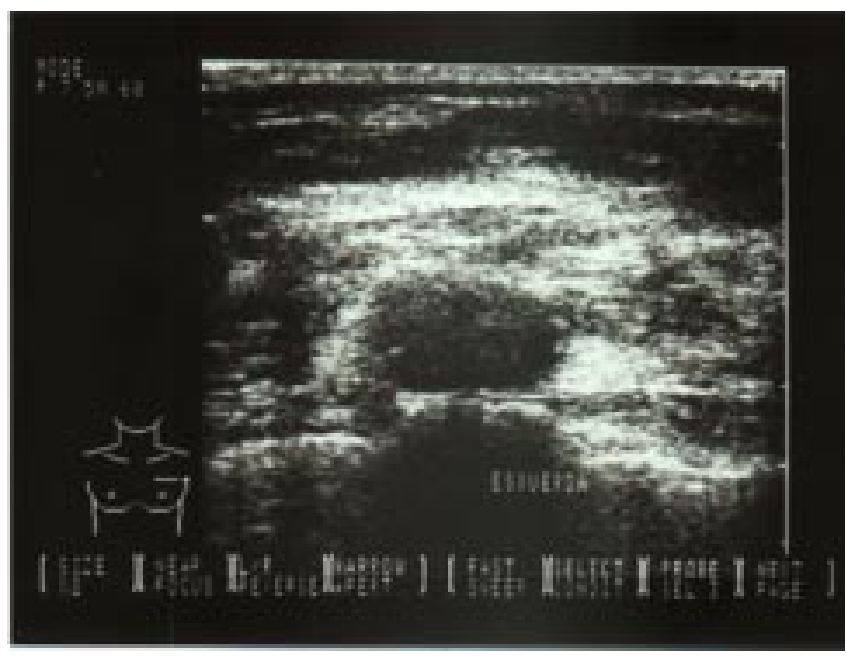

Figura 2 - Ultra-sonografia mamária: opacidade nodular sólida, heterogênea, mal delimitada em sua maior extensão, fazendo corpo com o músculo peitoral maior, localizada na união dos quadrantes superiores medindo $2,5 \mathrm{~cm}$ em seu maior eixo.

Dois meses após a consulta inicial foi realizada exérese do nódulo com o seguinte diagnóstico histopatológico: MACROSCOPIA: Massa de formato oval pesando $33 \mathrm{~g}$ e medindo 6 X 4,5 X $2 \mathrm{~cm}$, com superfície externa irregular constituída ora por gordura ora por músculo esquelético. A superfície de corte demonstra estrutura nodular medindo 4,5 X 3,1 cm, de coloração castanho-clara entremeada por faixas de tecido brancacento, de aspecto fibroso com limites mal definidos, que se estende a tecidos muscular e gorduroso adjacentes. MICROSCOPIA: Tumor composto por tecido conjuntivo fibroso abundante, muitas vezes formando massa densa de colágeno. De permeio, observa-se proliferação de células poligonais ou redondas, uniformes, com núcleos centrais, pequenos, vesiculosos e citoplasmas granulosos e eosinofílicos (Figura 3). Não se observam pleomofismo e figuras de mitose. As células dispôem-se em cordões ou ninhos separados por faixas de tecido conjuntivo fibroso. A neoplasia se estende aos tecidos gordurosos e muscular esquelético em padrão de crescimento infiltrativo comprometendo as margens da lesão. A pesquisa de receptores para estrogênio no tumor revelou-se negativa. O estudo imuno-histoquímico revelou positividade das células para enolase neuronal específica e negatividade para cromogramina, sinaptofisina e citoqueratina

Um ano após a cirurgia, a mamografia demonstrou densificação parenquimatosa assimétrica na união dos quadrantes superiores da mama esquerda profundamente, sugerindo cicatriz cirúrgica.

Dois anos depois da cirurgia notou-se nódulo mal definido de $1 \mathrm{~cm}$ de diâmetro, duro, fixo à 
parede costal e no quadrante superior externo da mama esquerda. A ultra-sonografia mamária mostrou-se como nódulo hipoecóico, heterogêneo, com área cística central adjacente ao músculo peitoral na região retroareolar profunda à esquerda (Figura 4). Diagnóstico: recidiva do TCG. Entretanto, a paciente não retornou mais as consultas.

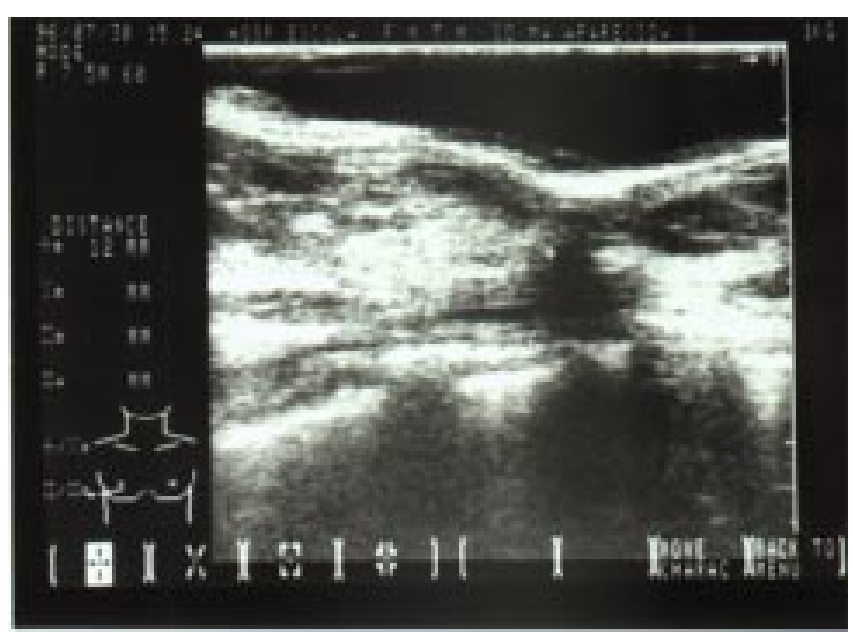

Figura 3 - Tumor composto de tecido conjuntivo denso, observa-se a proliferação de células poligonais ou redondas e a ausência de pleomorfismo e figuras de mitose.

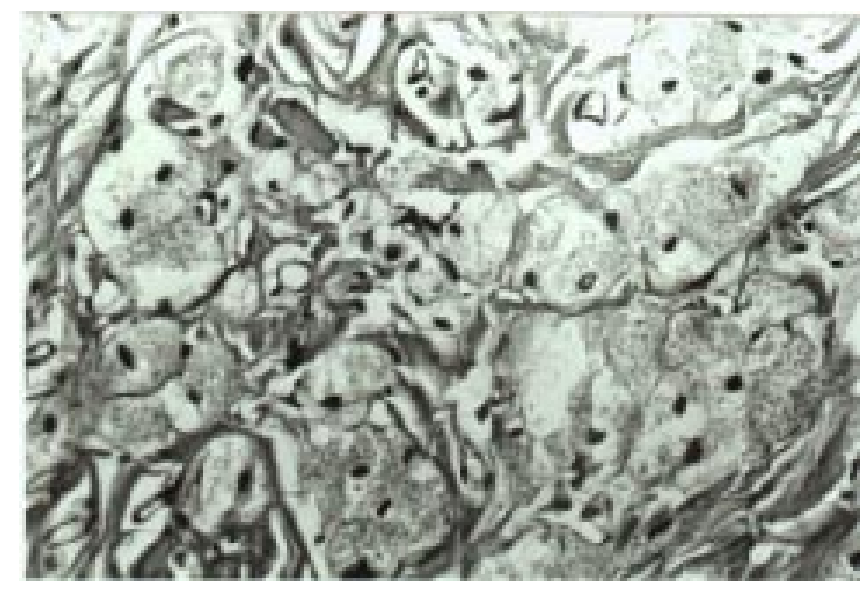

Figura 4 - Ultra-sonografia mamária (dois anos após cirurgia): opacidade nodular mal delimitada de $1,2 \mathrm{~cm}$, heterogênea, com diâmetro ântero-posterior maior que o transverso, fazendo corpo com o músculo peitoral maior, localizada na união dos quadrantes superiores.

\section{Discussão}

Cerca de 6 a 10\% dos tumores de células granulares se localizam na região da glândula mamária, sendo mais freqüentes em mulheres negras do que nas mulheres brancas. Geralmente, a paciente é pré-menopausada com idade média de 40 anos e com 19 meses de história de tumor em média. Neste relato, observou-se a longa história de presença do tumor: cerca de 10 anos. No que se refere à idade, o tumor era relatado pela paciente desde 50 anos de idade, idade esta próxima à descrita pela literatura ${ }^{1,3,8}$. O exame clínico desta paciente demonstrou que o nódulo era difuso com aproximadamente $6 \mathrm{~cm}$, limites imprecisos, duro, irregular, fixo ou fazendo corpo com o músculo peitoral maior. Nas descrições da literatura observa-se que tumor pode ser localizado na pele, tecido mamário ou músculo peitoral. Cerca de metade está confinado ao tecido subcutâneo e não envolve o tecido parenquimatoso mamário. Podem sugerir um fibroadenoma quando móveis, mas podem estar fixos com retração ou ulceração da pele simulando um carcinoma. A pele sobre o tumor pode estar pigmentada.

Quanto ao diagnóstico citológico, ele não foi feito pela punção-biópsia aspirativa, embora isto seja possivel ${ }^{7}$.

A mamografia pode apresentar aspecto benigno ou maligno ${ }^{4,8,9}$. Neste caso houve dificuldade na definição de nódulo, pois ele se encontrava bem próximo ao músculo peitoral maior. Não obstante apresentava opacidade nodular espiculada. Ao ultra-som observou-se um nódulo irregular compatível com processo neoplásico maligno, descrição esta semelhante ao relatado na literatura ${ }^{2}$.

Durante a cirurgia pode-se observar que o tumor geralmente é branco, bem circunscrito e não-encapsulado. Pode infiltrar os tecidos vizinhos levando à confusão com lesões malignas. Estas características foram encontradas na exérese do tumor deste relato. A exérese da lesão com margem e incluindo a pele sobrejacente é a cirurgia de escolha ${ }^{2}$.

O padrão esclerosante causado pelo abundante estroma colagenizado observado no presente caso já tinha sido notado anteriormente. Um grupo de investigadores relatou uma correlação direta entre a quantidade de fibrose estromal e a presença de elastose na lesão ${ }^{5}$. Esse padrão provocou o diagnóstico diferencial com fibromatose, porém a presença de células granulares em meio aos feixes de colágeno e a positividade dessas células para enolase neuronal específica confirmaram o diagnóstico de TCG. A origem histológica do tumor de células granulares é controversa. Inicialmente foi descrito como semelhante ao fibroblasto. Outros autores a definiram como originário da musculatura lisa, musculatura estriada, histiócitos, células indiferenciadas do mesênquima e células de Schwann. Pelo estudo da sua estrutura, dois tipos principais de células têm sido descritas ${ }^{3}$. A primeira, uma célula granular típica com grande número de grânulos membranosos contendo debris 
amórficos eletrodensos, possivelmente lisossomal. Entre estas células, existem outras com características de fibroblastos, com o retículo endoplasmático rugoso contendo material fibrilar e tubular. A presença de proteína S-100 tem sido demonstrada neste tumor ${ }^{6}$. A presença deste antígeno está relacionado com a especificidade para células do sistema neural, embora tenha sido descrita em tecidos de origem não-neural, como melanoma e tumores da bainha neural. A presença da proteína S-100 no tumor de células granulares pode evidenciar uma derivação de célula de Schwann. Tumores das células granulares benigno e maligno tem sido descrito como originários de nervos. A ausência de miosina e mioglobina tem sido descrito e demonstra que a origem não deve ser mioblástica. A presença de antígeno cárcinoembrionário é descrita e pode significar uma natureza blastomatosa ${ }^{2}$.

Em conclusão o tumor de células granular deve ser incluído no diagnóstico diferencial de nódulos mamários, apesar da sua raridade (1 tumor de células granular para 1000 carcinomas de mama). Sua característica clínica é importante para o diagnóstico, como também a utilização da punçãobiópsia aspirativa. A mamografia e ultra-sonografia são de pouca ajuda no esclarecimento. A congelação pode ser feita mas pode haver confusão com um carcinoma. O tratamento de escolha é a exérese da lesão e, se próximo à pele, com parte desta, respeitando a margem de $2 \mathrm{~cm}$.

\section{SUMMARY}

We describe a sclerosing granular cell tumor of the breast simulating fibromatosis. Clinically it simulates carcinoma because of its fibrous consistency and fixation to the greater pectoral muscle. The mammograms showed a rounded density with a slightly irregular margin in the upper, inner and outer quadrant of the left breast. Ultrasound showed a poorly defined solid lesion disrupting fascial planes. Clinical, radiological histological and therapeutica aspects are discussed.

KEY WORDS: Breast: benign diseases. Sclerosing granular cell tumor. Fibromatosis.

\section{Referências bibliográáicas}

1. Friedman RM, Hurwitt ES. Granular cell myoblastoma of the breast. Am Surg 1966; 112: 76-9.

2. Gordon AB, Fisher C, Palmer B, Greening WP. Granular cell tumour of the breast. Eur J Surg Oncol
1985; 11:269-273.

3. Lack EE, Worsham GG, Callihan MD, Crawford BE, Klappenbach S, Rowden G, Chun B. Granular cell tumour: a clinicopathologic study of 110 patients. J Surg Oncol 1980; 13: 301-16.

4. McCraken M, Hamal PB, Benson EA. Granular cell myoblastoma of the breast: a report of two cases. Br J Surg 1979; 66:819-21.

5. McMahon JN, Rigby HS, Davies JD. Elastosis in granular cell tumours: prevalence and distribution. Histopathology 1990; 16:37-41.

6. Mukai M. Immunohistochemical localization of S-100 protein and peripheral nerve myelin proteins (P2 protein, PO protein) in granular cell tumors. Am J Pathol 1983; 112: 139.

7. Sussman EB, Hajdu SI, Gray GF. Granular cell myoblastoma of the breast. Am J Surg 1973; 126: 669-70.

8. Turnbull AD, Huvos AG, Ashikari R, Strong EW. Granular cell myoblastoma of breast. NY State $\mathbf{J}$ Med 1971; 81: 971-8.

9. Willen R, Willen H, Balldin G, Albrechtsson U. Granular cell tumor of the mammary gland simulating malignancy. Virchows Arch 1984: 403: 391-400.

10.Vidyarthi SC. Granular cell myoblastoma of the breast. Arch Surg 1969; 98: 662-7. 